\title{
EFFECT OF THE AIR MOTION ON THE HEAT TRANSPORT BEHAVIOUR OF WALL STRUCTURES
}

\author{
F. SZODRAI a Á. LAKATOS \\ Department of Building Services and Building Engineering, University of Debrecen, Faculty of Engineering, \\ H-4028 Debrecen, Ótemető u. 2-4, Hungary \\ ${ }^{a}$ E-mail: szodrai@eng.unideb.hu \\ bE-mail: alakatos@eng.unideb.hu
}

\begin{abstract}
The laboratory investigations of the heat transfer properties of wall structures are very significant from the point of view of designing the buildings. In this article measurements and calculations will be presented in order to manifest the effect of the forced and un-forced convection of air at the cold surface of the wall. A steady-state method for measuring the thermal resistance of wall structures with Hukseflux apparatus is presented in this article. The measurements were accomplished through, firstly on an un-insulated inbuilt plaster/brick/plaster wall construction and later it was covered with a $0.013 \mathrm{~m}$ thick aerogel layer blanket. Aerogels are nanoporous lightweight materials, were discovered more than 70 years ago. In these years their applications are truly spread over. During the investigations the wall structures were tested without forcing the air to motion, and then measurements were carried both on the insulated and un-insulated wall structures, where the movement of the air was forced by a ventilator from three different directions with the same $1 \mathrm{~m} / \mathrm{s}$ velocity near the wall.
\end{abstract}

Keywords: heat transfer coefficient, similitude modeling, thermal resistance

\section{Introduction}

In the European Union, buildings account for about $20-40 \%$ of the total energy consumption [1-3]. One of the most important actions to reduce the energy loss of buildings is their thermal insulation. Aerogel is said to be a state-of-the-art thermal insulation solution, and looks to be the most promising with the highest potential. Aerogel blankets/panels have started to be used to insulate building walls. Their use as a plinth insulation is minor. However, commercially available stateof-the-art aerogels have been reported to have thermal conductivities under $0.02 \mathrm{~W} / \mathrm{m} \mathrm{K}$ at ambient pressure. A very interesting aspect of aerogels is that they can be produced as either opaque (in a blanket), translucent or transparent materials, thus enabling a wide range of possible building applications. These blankets were developed as an insulation material based on silica aerogels. Silica aerogel is an aggregate, nano-porous, insulation material, produced using a sol-gel process and supercritical evaporation technology. Material has reasonable insulating performance due to its nano-porous structure (several to tens of nanometers) and very small solid grain size $(2-5 \mathrm{~nm})$ [4-8].

In this article measurements are presented to help the optimization of the thermal design process of buildings. In recent articles it was demonstrated that the laboratory investigation of the heat transfer coefficients is significant. Wind produces three different types of effects on structure: static, dynamic and aerodynamic. The response of load depends on type of structure. The air in motion (wind) has impact in the heat loss of building structures, since in the building energy consumption. There are many established analytical and experimental expressions of these coefficients for different flow types and ventilation modes.

The convective heat flux $q_{c}\left(\mathrm{~W} / \mathrm{m}^{2}\right)$ from the building above ground external surface is an important heat transfer process in the simulation of building energy performance. Usually, $q_{c}$ is expressed as:

$$
q_{c}=h_{c}\left(T_{w}-T_{a}\right),
$$

where $h_{c}\left(\mathrm{~W} / \mathrm{m}^{2} \mathrm{~K}\right)$ is the convective heat transfer coefficient (CHTC), $T_{w}(\mathrm{~K})$ is the building surface temperature, and $T_{a}(\mathrm{~K})$ is the air temperature. The coefficient $h_{c}$ depends on several factors, for examples building geometry, surface roughness, air flow pattern, and wind speed $V(\mathrm{~m} / \mathrm{s})$ at some reference position. It is generally accepted that conductive and radiative heat transfer are now reasonably well-described in building thermal models. However, the only computa-

This is an open-access article distributed under the terms of the Creative Commons Attribution-NonCommercial 4.0 International License (https://creativecommons.org/licenses/by-nc/4.0/), which permits unrestricted use, distribution, and reproduction in any medium for non-commercial purposes, provided the original author and source are credited, a link to the CC License is provided, and changes - if any - are indicated. 
tionally feasible option for calculating the surface heat transfer within this type of model is to utilize $h_{c}$ in the formulation given in Eq. (1) [9-15].

\section{Materials and methods}

This paper is mainly based on steady-state heat transfer measurement carried out in-built wall structures with Hukseflux heat flow meter apparatus. In order to measure the thermal resistance of a layer structure, an isolated chamber is available. The chamber is surrounded as well as divided into two rooms (cold and warm) with $2 \times 3 \mathrm{~m}$ areas each, by $0.5 \mathrm{~m}$ thick EPS 200 insulation system. The cold room can be cooled down to $257 \mathrm{~K}$ by three separated cryogenics. The warm room can be heated up to $298 \mathrm{~K}$ by a basic portable electric radiator. In the EPS dividing-wall $0.52 \mathrm{~m}$ over the ground a brick wall window, with $0.25 \mathrm{~m}$ thickness and $1.44 \mathrm{~m}^{2}$ surface areas can be found. This brick wall is mortared with $0.015 \mathrm{~m}$ plaster (this is a conventional Ytong-type mortar) both at the warm and the cold side. Then the wall was covered with a $0.013 \mathrm{~m}$ thick aerogel insulation material. The measurement orders are clearly presented and written in our recent papers $[8,16-18]$.

\subsection{Measurements with Hukseflux apparatus}

Hukseflux (HF) HFP01 heat flux sensors serve the reason to measure the heat flux that flows through the object in which it is incorporated or on which it is mounted. The best accuracy in the measurement values can be reached after the heat transfer through the wall structures reaches the steady-state stage. Besides, thermopile sensors measure the differential temperature across the ceramics-plastic composite body of HFP01. This instrument can measure the Heat Flux, and the $R$ value of building envelopes according to the ISO 9869 ,
ASTM C1046 and ASTM C1155 standards. The measurements were carried out by using two HF sensors fixed up at different points on the wall. To measure the air and wall temperatures at both warm and cold sides 2 pairs of thermo-couples belong to this apparatus. If one measures the temperature with the Hukseflux thermocouples on the wall first and then in the air one can calculate the surface heat transfer resistances both for the cold and warm sides. By using this apparatus one can reach an accurate value for the thermal resistance ( $R$ value) measured by using the following equation,

$$
R_{w}=\Delta T_{w} / \Phi
$$

where $\Delta T_{w}$ in $\mathrm{K}$ is the average wall temperature difference between the warm and cold sides of the wall and $\Phi \mathrm{HF}$ is the average of the measured heat flux and $R_{w}$ is the resistance of the wall. Afterwards, the air temperature values were registered with the thermocouples of the Hukseflux apparatus and from their difference $\Delta T_{a}$ can be reached.

$$
R_{a}=\Delta T_{a} / \Phi
$$

where $R_{a}$ is the total $R$ value.

$$
\begin{aligned}
& R_{a}=R_{s T}+R_{w}, \\
& R_{s T}=R_{a}-R_{w},
\end{aligned}
$$

and $R_{s T}$ is the total surface heat transfer resistance, containing the coefficients of both sides (cold, warm).

$$
R_{s T}=R_{i s}+R_{e s}=1 / h_{i s}+1 / h_{e s}=1 / h_{i s, e s},
$$

where $h_{i s}, h_{e s}$ and $R_{i s}, R_{e s}$ are the internal and external surface heat transfer coefficients and resistances carried out by the HF method. If there is forced convec-

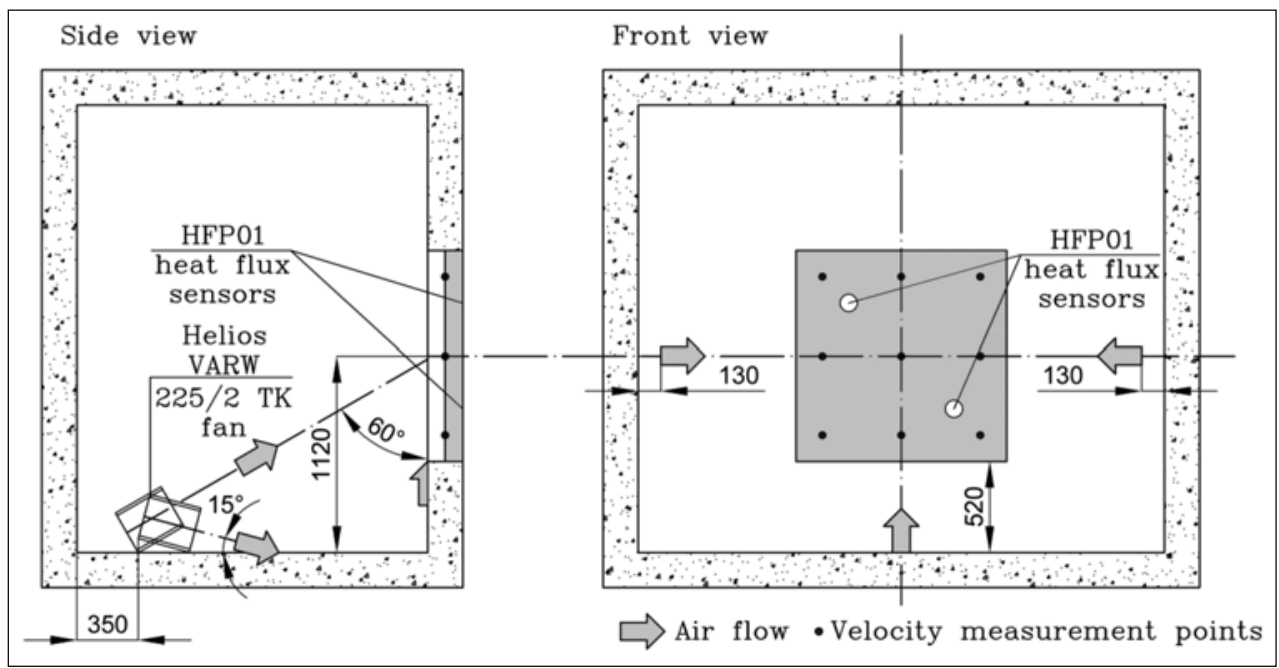

Fig. 1. Schematic figure of the measurement 
tion neither at the warm nor in the cold sides $h_{i s}$ and $h_{e s}$ can be managed together as $h_{i s, e s}$ and can be separated to two equal parts $[8,16-18]$.

\subsection{The motion of the air}

For the forced air convection, a type Helios VARW $225 / 2$ TK $350 \mathrm{~W}$ axial fan was applied. The main goal of its was to make a homogeneous air motion with $1 \pm$ $0.1 \mathrm{~m} / \mathrm{s}$ velocity along the measured surface from the left side, from the right side and from downer.

Figure 1 helps us to understand the positions of the fan. In this figure the grey arrow represents the direction of the flow. In the front view, we can see the attack point of the flow. When the attack came from the sides, we put the fan adjacent to the wall and targeted the middle height of the measured surface (grey rectangle). In these cases the angle between the axis of the flow and the measured surface was $60^{\circ}$. In the third case, when we blew from the middle and the fan was tilted to the floor to help the distribution of the flow along the surface.

To ensure the homogeneous velocities we used a rotating vane anemometer at nine different point on the measured surface. The points where the velocities of the flow were measured were marked with a black dot in Fig. 1. The distance between the measurement points were $0.45 \mathrm{~m}$.

With these assumptions, we had three-forced and a natural convection, in addition we repeated the measurement without the insulation, since we had eight cases in total. To shorten the name of the cases Table 1 was compiled.

Table 1. The measurement cases with the codes

\begin{tabular}{lc}
\hline Name & Code \\
\hline Insulated wall & I \\
Insulated wall blown from left & IL \\
Insulated wall blown from right & IR \\
Insulated wall blown from below & IB \\
Un-insulated wall & U \\
Un-insulated wall blown from left & UL \\
Un-insulated wall blown from right & UR \\
Un-insulated wall blown from below & UB \\
\hline
\end{tabular}

\subsection{Calculations for $\mathrm{h}_{\mathrm{c}}$ with similitude modeling}

For calculating the heat transfer coefficient by simulate modeling two cases should be discussed. At first if we have free convection, secondly if we have forced convection. For the calculations the following assumptions have to be taken into account:

1) Steady-operating conditions exist.
2) Radiation effects are negligible.

3) Air is an ideal gas with constant properties (the properties only depend from the temperature).

In order to reach the convective heat transfer coefficient, the Nusselt number should be found.

$$
N u=h_{c} L / \lambda
$$

where $L(\mathrm{~m})$ is the length of the wall, and $\lambda(\mathrm{W} / \mathrm{m} \mathrm{K})$ is the thermal conductivity of the air at a given temperature. We have to further use the following equation:

$$
N u=f(R e, G r, P r)
$$

where $R e, G r, P r$ are the Reynolds, the Grasshof and the Prandtl numbers.

If the convection is free - i.e. there are no external forces to move the air - the Nusselt number can be calculated as:

$$
N u=C(G r \cdot P r)^{n},
$$

where $C$ and $n$ are constants, but they depend from the multiplication of the $G r$ and $\operatorname{Pr}$ numbers.

From the result of the following equation $C$ and $n$ can be found from tables containing the data of the air at a given temperature:

$$
G r \cdot \operatorname{Pr}=g L^{3} \Delta T \cdot \operatorname{Pr} \cdot \beta / v^{2},
$$

where $g$ gravity $\left(\mathrm{m} / \mathrm{s}^{2}\right), \Delta T=T_{w}-T_{a}(\mathrm{~K})$ is the temperature difference between the air and the surface, and $\beta(1 / \mathrm{K})$ is their average value and $v\left(\mathrm{~m}^{2} / \mathrm{s}\right)$ is the viscosity.

It should be further assumed that the critical Reynolds number is $R e_{\mathrm{cr}}=5 \cdot 10^{5}$, if the motion of the air is forced, where the Reynolds number in function of the air velocity ( $V$ in $\mathrm{m} / \mathrm{s}$ ) parallel to the surface is:

$$
R e=V L / v,
$$

in which case for the Nusselt number

$$
N u=0.064 \operatorname{Re}^{0.5} \cdot \operatorname{Pr}^{0.33}
$$

can be reached.

From the Nusselt numbers the $h_{c}$ can be obtained by using Eq. (7)

\subsection{The calculations for the heat transfer coefficients by using the standard}

The MSZ EN ISO 6946:2008 standard gives a simplified method to calculate the heat transfer coefficients. By using the following equation the heat transfer co- 
efficient can be found as the function of only the wind speed adjacent to the surface:

$$
h_{c}=4+4 V .
$$

This standard also gives us information about the relation between the wind speed and the external surface resistance. For example, the surface resistance is $0.08 \mathrm{~m}^{2} \mathrm{~K} / \mathrm{W}$ at $1 \mathrm{~m} / \mathrm{s}$ wind speed.

\subsection{Calculations of the surface resistance by using the standard}

The surface resistance can be calculated from the following way where the $h_{c}$ and $h_{r}$ is the convective and radiative heat transfer coefficients, respectively:

$$
R s=1 /\left(h_{c}+h_{r}\right)
$$

The radiative heat transfer coefficient depends on the hemispherical emissivity $\varepsilon$ of the surface that is usually 0.9 for external surface and $h_{r 0}$ is the radiation coefficient of a black body surface:

$$
h_{r}=\varepsilon h_{r 0} \text {. }
$$

The calculation of the radiative coefficient $h_{r 0}$ for a black body surface is the following:

$$
h_{r 0}=4 \sigma T_{m}^{3}
$$

where $T_{m}$ is the mean thermodynamic temperature of the surface and the surrounding air in K, moreover $\sigma$ is the Stefan-Boltzmann constant.

\begin{tabular}{|c|c|c|c|c|c|c|c|}
\hline \multirow[t]{2}{*}{ Code } & \multirow{2}{*}{$\begin{array}{c}\varphi \\
{\left[\mathrm{W} / \mathrm{m}^{2}\right]}\end{array}$} & \multicolumn{3}{|c|}{ Wall } & \multicolumn{3}{|c|}{ Air } \\
\hline & & $\Delta T\left[{ }^{\circ} \mathrm{C}\right]$ & $T_{\text {warm }}\left[{ }^{\circ} \mathrm{C}\right]$ & $T_{\text {cold }}\left[{ }^{\circ} \mathrm{C}\right]$ & $\Delta T\left[{ }^{\circ} \mathrm{C}\right]$ & $T_{\text {warm }}\left[{ }^{\circ} \mathrm{C}\right]$ & $T_{\text {cold }}\left[{ }^{\circ} \mathrm{C}\right.$ \\
\hline I & 27.50 & 32.98 & 21.61 & -11.37 & 41.44 & 24.43 & -17.01 \\
\hline IL & 30.54 & 34.57 & 20.82 & -13.75 & 40.89 & 24.52 & -16.37 \\
\hline IR & 29.44 & 34.60 & 20.95 & -13.65 & 40.64 & 24.51 & -16.13 \\
\hline IB & 30.99 & 34.65 & 20.90 & -13.75 & 41.03 & 24.56 & -16.47 \\
\hline Average & 30.32 & 34.60 & 20.89 & -13.72 & 40.85 & 24.53 & -16.32 \\
\hline $\mathrm{U}$ & 51.73 & 27.13 & 19.13 & -8.00 & 39.93 & 23.92 & -16.00 \\
\hline UL & 58.39 & 30.84 & 18.61 & -12.23 & 41.41 & 24.94 & -16.47 \\
\hline UR & 57.84 & 30.24 & 18.69 & -11.54 & 40.59 & 24.62 & -15.97 \\
\hline UB & 58.61 & 31.00 & 18.39 & -12.62 & 41.47 & 24.91 & -16.56 \\
\hline Average & 58.28 & 30.69 & 18.56 & -12.13 & 41.16 & 24.82 & -16.33 \\
\hline
\end{tabular}

$$
\sigma=5.67 \cdot 10^{-8} \mathrm{~W} /\left(\mathrm{m}^{2} \mathrm{~K}^{4}\right) .
$$

\begin{tabular}{|c|c|c|c|c|c|c|}
\hline \multirow[b]{2}{*}{ Code } & \multicolumn{4}{|c|}{$\begin{array}{c}\text { Thermal resistance } \\
{\left[\mathrm{m}^{2} \mathrm{~K} / \mathrm{W}\right]}\end{array}$} & \multicolumn{2}{|c|}{$\begin{array}{c}\text { Heat transfer } \\
\text { coefficients }\left[\mathrm{W} / \mathrm{m}^{2} \mathrm{~K}\right]\end{array}$} \\
\hline & $\begin{array}{l}\text { Wall } \\
\left(R_{W}\right)\end{array}$ & $\begin{array}{l}\text { Air surroundings } \\
\qquad\left(R_{a}\right)\end{array}$ & $\begin{array}{c}\text { Surface total } \\
\quad\left(R_{S T}\right)\end{array}$ & $\begin{array}{c}\text { External surface } \\
\left(R_{e s}\right)\end{array}$ & $h_{i s}$ & $h_{e s}$ \\
\hline I & 1.20 & 1.51 & 0.31 & 0.15 & 6.50 & 6.50 \\
\hline IL & 1.13 & 1.34 & 0.21 & 0.05 & 6.50 & 18.77 \\
\hline IR & 1.18 & 1.38 & 0.21 & 0.05 & 6.50 & 19.46 \\
\hline IB & 1.12 & 1.32 & 0.21 & 0.05 & 6.50 & 19.13 \\
\hline Average & 1.14 & 1.35 & 0.21 & 0.05 & 6.50 & 19.12 \\
\hline $\mathrm{U}$ & 0.52 & 0.77 & 0.25 & 0.12 & 8.08 & 8.08 \\
\hline UL & 0.53 & 0.71 & 0.18 & 0.06 & 8.08 & 17.44 \\
\hline UR & 0.52 & 0.70 & 0.18 & 0.06 & 8.08 & 18.09 \\
\hline UB & 0.53 & 0.71 & 0.18 & 0.05 & 8.08 & 18.23 \\
\hline Average & 0.53 & 0.71 & 0.18 & 0.06 & 8.08 & 17.92 \\
\hline
\end{tabular}

Table 2. Measured values

Table 3. Calculated thermal resistances 
Moreover, from Eq. (14):

$$
h_{c}=1 / R_{e s}-h_{r},
$$

where in our case $R_{e s}$ was reached from the measurements.

\section{Results and discussion}

\subsection{Results of the measurements}

In this section we present the results of the measurements and the calculations reached from them in combination with the standard. As mentioned above, during the measurements the heat flux and the temperature on the surface of the external side of the wall, as well as the temperature of the air were registered. The results of each measurement can be seen in Table 2 both for the insulated and for the un-insulated cases, moreover, if the convection of the air was forced or not. Besides the heat fluxes and the temperatures the temperature differences for the air and for the wall are presented in the table. The calculated thermal resistances can be seen in Table 6 . The wall with the $1.13 \mathrm{~cm}$ thick aerogel insulation has doubled the thermal resistance compared to the un-insulated wall's.

From the 2nd, 3rd and 4th, moreover from the 7th, 8th and 9th lines of the table interesting results can be seen. For both cases (insulated/un-insulated) where the convection of the air was forced one can observe significant deviance neither in the heat fluxes nor in the temperatures, since they could be managed together with an average. It means that only the air velocity $(1 \mathrm{~m} / \mathrm{s})$ and the insulation have effect in the heat transfer, the direction of the ventilator does not have. To put it simply for all blowing directions the same phenomena can be expected.
In Table 3 the calculated values can be found by using the Eqs (2) to (6). Here has to be mentioned again that for the forced flows, both for the insulated and for the un-insulated cases can be managed together as averages. By using Eq. (6) if we fix $h_{i s}$ to constants $\left(6.5\right.$ and $\left.8.08 \mathrm{~W} / \mathrm{m}^{2} \mathrm{~K}\right) h_{e s}$ can be calculated what contains the $h_{c}$ and $h_{r}$ for the cold sides. Belonging to this about 19 and approximately $18\left(\mathrm{~W} / \mathrm{m}^{2} \mathrm{~K}\right)$ can be reached for $h_{e s}$ of the insulated and un-insulated cases. Here should be mentioned that $R_{e s}$ is the reciprocal value of $h_{e s}$.

\subsection{Calculations of the surface resistance by using the similitude modelling}

By using the Eqs (7) to (12) with the above-mentioned assumptions the convective part $\left(h_{c 1}\right)$ of the surface heat transfer coefficient $(h)$ can be estimated both for forced and unforced convection. In our cases we only investigate the cold sides because there were no forces to move the air at the warm sides.

Constants during the calculation is the gravity $9.81 \mathrm{~m} / \mathrm{s}^{2}$, length $1.2 \mathrm{~m}, C$ for natural convection is 0.14 and for forced convection is 0.5 and $n=1 / 3$. From the table one can see that the convective part is about 3.1 to for the insulated wall $3.52 \mathrm{~W} / \mathrm{m}^{2} \cdot \mathrm{K}$ for the un-insulated if there is no forced convection, however, for forced convection they are approximately the same (3.54 and $3.55 \mathrm{~W} / \mathrm{m}^{2} \cdot \mathrm{K}$ ), see Table 4.

\subsection{The calculations of the surface resistance by using the standard}

In the above-mentioned standard a calculation method both for $h_{c 1}$ and for $h_{r}$ can be found (Eqs (13)-(17)). By using the suggestions of the standard calculations

Table 4. The data for the similitude modelling

\begin{tabular}{|c|c|c|c|c|c|c|c|c|c|}
\hline Code & $\begin{array}{l}G r \\
{[-]}\end{array}$ & $\begin{array}{l}\operatorname{Re} \\
{[-]}\end{array}$ & $\begin{array}{c}\lambda \\
{[\mathrm{W} / \mathrm{m} \mathrm{K}]}\end{array}$ & $\begin{array}{c}v \\
{\left[10^{-5} \cdot \mathrm{m}^{2} / \mathrm{s}\right]}\end{array}$ & $\begin{array}{l}\mathrm{Pr} \\
{[-]}\end{array}$ & $\begin{array}{c}T_{\text {average }} \\
{[\mathrm{K}]}\end{array}$ & $\begin{array}{l}\Delta T \\
{[\mathrm{~K}]}\end{array}$ & $\begin{array}{l}N u \\
{[-]}\end{array}$ & $\begin{array}{c}h_{c 1} \\
{\left[\mathrm{~W} / \mathrm{m}^{2} \mathrm{~K}\right]}\end{array}$ \\
\hline I & $1.66 \cdot 10^{9}$ & inapp. & 0.0233 & 1.26 & 0.7137 & 258.95 & 5.64 & 160.00 & 3.10 \\
\hline IL & inapp. & 95147 & 0.0232 & 1.26 & 0.7140 & 258.08 & 2.62 & 183.06 & 3.54 \\
\hline IR & inapp. & 95193 & 0.0232 & 1.26 & 0.7140 & 258.25 & 2.48 & 183.10 & 3.54 \\
\hline IB & inapp. & 95133 & 0.0232 & 1.26 & 0.7140 & 258.03 & 2.72 & 183.05 & 3.54 \\
\hline Average & inapp. & 95158 & 0.0232 & 1.26 & 0.7140 & 258.12 & 2.60 & 183.07 & 3.54 \\
\hline U & $2.37 \cdot 10^{9}$ & inapp. & 0.0234 & 1.25 & 0.7128 & 261.14 & 8.00 & 179.98 & 3.52 \\
\hline UL & inapp. & 95339 & 0.0233 & 1.26 & 0.7137 & 258.79 & 4.24 & 183.22 & 3.55 \\
\hline UR & inapp. & 95501 & 0.0233 & 1.26 & 0.7135 & 259.38 & 4.43 & 183.36 & 3.56 \\
\hline UB & inapp. & 95275 & 0.0232 & 1.26 & 0.7138 & 258.55 & 3.94 & 183.17 & 3.55 \\
\hline Average & inapp. & 95371 & 0.0233 & 1.26 & 0.7137 & 258.91 & 4.20 & 183.25 & 3.55 \\
\hline
\end{tabular}

(innapp. means inappropriate) 
Table 5. MSZ EN ISO 6946:2008 calculations

\begin{tabular}{lccccc}
\hline Equation & 15 & 16 & & 18 & 13 \\
\hline Code & $\begin{array}{c}h_{r} \\
{\left[\mathrm{~W} / \mathrm{m}^{2} \mathrm{~K}\right]}\end{array}$ & $\begin{array}{c}h_{r 0} \\
{\left[\mathrm{~W} / \mathrm{m}^{2} \mathrm{~K}\right]}\end{array}$ & $\begin{array}{c}T_{m} \\
{[\mathrm{~K}]}\end{array}$ & $\begin{array}{c}h_{c 2} \\
{\left[\mathrm{~W} / \mathrm{m}^{2} \mathrm{~K}\right]}\end{array}$ & $\begin{array}{c}h_{c 3} \\
{\left[\mathrm{~W} / \mathrm{m}^{2} \mathrm{~K}\right]}\end{array}$ \\
\hline I & 3.54 & 3.94 & 259.0 & 2.96 & 4 \\
IL & 3.51 & 3.90 & 258.1 & 15.27 & 8 \\
IR & 3.52 & 3.91 & 258.3 & 15.94 & 8 \\
IB & 3.51 & 3.90 & 258.0 & 15.62 & 8 \\
\hline Average & 3.51 & 3.90 & 258.1 & 15.61 & 8 \\
\hline U & 3.64 & 4.04 & 261.1 & 4.45 & 4 \\
UL & 3.54 & 3.93 & 258.8 & 13.91 & 8 \\
UR & 3.56 & 3.96 & 259.4 & 14.53 & 8 \\
UB & 3.53 & 3.92 & 258.6 & 14.70 & 8 \\
\hline Average & 3.54 & 3.94 & 258.9 & 14.38 & 8 \\
\hline
\end{tabular}

Table 6. Values of $h_{c}$

\begin{tabular}{lccc}
\hline Equation & $9 / 12$ & 18 & 13 \\
\hline Code & $h_{c 1}\left[\mathrm{~W} / \mathrm{m}^{2} \mathrm{~K}\right]$ & $h_{c 2}\left[\mathrm{~W} / \mathrm{m}^{2} \mathrm{~K}\right]$ & $h_{c 3}\left[\mathrm{~W} / \mathrm{m}^{2} \mathrm{~K}\right]$ \\
\hline I & 3.10 & 2.96 & 4 \\
IL & 3.54 & 15.27 & 8 \\
IR & 3.54 & 15.94 & 8 \\
IB & 3.54 & 15.62 & 8 \\
\hline Average & 3.54 & 15.61 & 8 \\
\hline U & 3.52 & 4.45 & 4 \\
UL & 3.55 & 13.91 & 8 \\
UR & 3.56 & 14.53 & 8 \\
UB & 3.55 & 14.70 & 8 \\
\hline Average & 3.55 & 14.38 & 8 \\
\hline & & & 8 \\
\hline
\end{tabular}

were executed in order to find the coefficients, and the results are presented in Table 5.

To put it simple Table 6 was created in order to make the comparison between the different $h_{c}$ values as a result of the similitude modeling $\left(h_{c 1}\right)$, the measurements $\left(h_{c 2}\right)$ and the standard $\left(h_{c 3}\right)$.

As we can see from Table 6, by using Eq. (13) (taken from the standard), as well the results from the similitude modeling insignificancy of the insulation can be observed in contrast to the measurement results where the insulation has measurable effect. However it has to be mentioned that the direction of the initial blowing of the air is negligible in all cases, only the formed flow (in our case: laminar flow parallel to the surface), since the velocity near the surface is the influencing factor.

\section{Conclusions}

The main conclusion is that has been used successfully the building physics laboratory to obtain heat transfer coefficients CHTC for an insulated and un-insulated wall. This paper has provided an extensive review of models to calculate exterior convective heat transfer coefficients $\left(h_{c}\right)$. Convective heat transfer coefficients for walls were experimentally measured in different positions in the cases of free and forced flows. It is to be noted that in this study solar gains have not been taken into account. Three different coefficient was estimated and were compared pointing out the similarities and the differences. We revealed that the direction of the initial blowing of the air is negligible in all cases, only the 
formed flow, since the velocity near the surface is the influencing factor.

\section{Acknowledgement}

This paper was supported by the János Bolyai Research Scholarship of the Hungarian Academy of Sciences.

\section{References}

[1] Kalmár F., Kalmár T. (2012), Interrelation between mean radiant temperature and room geometry. Energy and Buildings, 55, 414-421.

[2] Kalmár F., Kalmár T. (2007), Energy class. building structure and solar gains. Journal of Harbin Institute of Technology (New Series), 14, 81-84.

[3] Borodinecs A., Kreslins A. (2008), Reduction of cooling and heating loads using building envelopes with controlled thermal resistance. In: Proceedings of Conference: Air Conditioning and the Low Carbon Cooling Challenge - Windsor, 2008, Conference Code 89553

[4] Galliano R., Ghazi Wakili K., Stahl Th., Binder B., Daniotti B. (2016), Performance evaluation of aerogel-based and perlite-based prototyped insulations for internal thermal retrofitting: HMT model validation by monitoring at demo scale. Energy and Buildings, 126, 275-286.

[5] Ghazi Wakili K., Stahl Th., Heiduk E., Schuss M., Vonbank R., Pont U., Sustr C., Wolosiuk D., Mahdavi A. (2015), High performance aerogel containing plaster for historic buildings with structured façades. Energy Procedia, 78, 949-954. doi: 10.1016/j.egypro.2015.11.027

[6] Jelle B. P. (2011), Traditional. state-of-the-art and future thermal building insulation materials and solutions - Properties, requirements and possibilities. Energy and Buildings, 43, 2549-2563.

[7] Stahl Th., Brunner S., Zimmermann M., Ghazi Wakili K. (2012), Thermo-hygric properties of a newly developed aerogel based insulation rendering for both exterior and interior applications. Energy and Buildings, 44, 114-117.
[8] Lakatos. A. (2017), Comprehensive thermal transmittance investigations carried out on opaque aerogel insulation blanket. Materials and Structures, 50 1; 2. DOI: 10.1617/ s11527-016-0876-7

[9] Chávez-Galán J., Almanza R., Rodríguez Cuevas N. (2014), Convective heat transfer coefficients: experimental estimation and its impact on thermal building design for walls made of different Mexican building materials. Concreto y Cemento, Investigación y Desarrollo, 5(2), 26-38.

[10] Dodog Z., Halász Gy. (2016), Az épülethatároló szerkezetek hőátadási tényezőinek elemzése. Magyar Épületgépészet, 10.

[11] Davies M., Martin C., Watson M., Ni Riain C. (2005), The development of an accurate tool to determine convective heat transfer coefficients in real buildings. Energy and Buildings, 37, 141-145.

[12] Martynenko O., Khramtso P. (2005), Free-Convective Heat Transfer. Springer. The Netherlands.

[13] Khalifa A. J. N. (2001), Natural convective heat transfer coefficient: a review I. Isolated vertical and horizontal surfaces. Energy Conversion and Management. 42, 491-504.

[14] Obyn S., Moeseke G. (2015), Variability and impact of internal surfaces convective heat transfer coefficients in the thermal evaluation of office buildings. Applied Thermal Engineering, 87, 258-272.

[15] Anders Ohlsson K. E., Östin R., Grundberg S., Olofsson T. (2016), Dynamic model for measurement of convective heat transfer coefficient at external building surfaces. Journal of Building Engineering, 239-245.

[16] Lakatos A. (2014), Measurements of thermal properties of different building materials. Advanced Materials Research, 1016, 733-737.

[17] Lakatos A., Csáky I., Kalmár F. (2015), Thermal conductivity measurements with different methods: A procedure for the estimation of the retardation time. Materials and Structures, 48, 5, 1343-1353.

[18] Lakatos A. (2016), Measurement of the decrement factor of different wall structures. WSEAS Transactions on Heat and Mass Transfer, 11, 1, 5. 